\section{Exploring the implications of HPV infection for head and neck cancer}

\author{
Nigel Field, ${ }^{1}$ Matt Lechner ${ }^{2}$
}

Over recent years, human papillomavirus (HPV) has been shown to be a major risk factor for head and neck squamous cell cancer (HNSCC), and particularly oropharyngeal squamous cell carcinoma. ${ }^{1} 2$ In 2007, the International Agency for Research on Cancer recognised HPV as a carcinogen associated with malignant transformation in this subset of head and neck cancers. It is now well established that HPV-induced oropharyngeal cancers and those caused by other factors (such as smoking and alcohol abuse-a combination of heavy smoking and drinking leads to an almost 50-fold increased risk of oral and pharyngeal cancer ${ }^{3}$ ) are two separate entities, with distinct aetiologies, clinical characteristics, prognoses and a different epidemiology and molecular basis. $^{4}$

The incidence of HPV-associated HNSCC has risen rapidly in the Western world over the past 40 years. $^{5-8}$ For example, there has been an estimated threefold increase in tonsillar cancer during this period, ${ }^{9}$ and the overall estimated population-level incidence of HPV-positive oropharyngeal cancer, which was 2.6 per 100000 in the USA in $2004,{ }^{6}$ is set to triple again in the next 20 years. ${ }^{10}$ Interestingly, the overall incidence of HNSCC is falling at a time when the incidence of HPV-induced cancer has risen, with the result that the proportion of HPV-positive tonsillar cases has risen from $<25 \%$ in the 1970 s to $93 \%$ of cases by 2007 in parts of the developed world. ${ }^{7}$ It is also noteworthy that those affected tend to be younger patients (age $<50$ years) who are frequently nonsmokers, and that men seem to be at higher risk of developing this type of cancer than women. ${ }^{11}$

There is good evidence for sexual acquisition of oropharyngeal HPV infection, ${ }^{12}$ and an intriguing hypothesis is that the increase in HPV-associated HNSCC might be driven in part and predated by changes in population sexual behaviour. In the UK, for example, a significant increase in the proportion of

${ }^{1}$ Research Department of Infection \& Population Health, University College London, London, UK; ${ }^{2}$ UCL Cancer Institute, University College London, London, UK people reporting oral sex in the past year occurred between 1990 and 2000, and this proportion remained high between 2000 and $2010 .{ }^{14}$ Similarly, around $75 \%$ of men and $65 \%$ of women born between 1946 and 1955 reported ever giving or receiving oral sex, but this proportion was over $90 \%$ among men and women born 20 years later. That oral sex is an almost ubiquitous exposure probably explains why some of the largest and methodologically most robust studies have failed to find an association between reporting oral sex and the detection of oral HPV infection. ${ }^{15}$ However, much remains to be understood about the acquisition and persistence of oral HPV infection, and the evidence for changes in sexual behaviour driving increases in $\mathrm{HPV}$-associated HNSCCs is still circumstantial.

The increase in HPV-induced HNSCC has important clinical implications because this subset of cancers responds better to chemotherapy and radiotherapy (82\% vs $55 \%$ response rate for HPV-negative cases) and has a better disease-free and overall survival $\left(95 \%\right.$ vs $62 \%$ at 2 years). ${ }^{16}$ Patients with HPV-induced HNSCC have a lower incidence of second primary tumours, as well as decreased risk (or cumulative incidence) of relapse. ${ }^{17} 18$

In the same way that HPV testing has been incorporated into the cervical cancer screening programme for samples with borderline or mild dyskaryosis to inform clinical management, ${ }^{19}$ there is now interest in developing a valid and reliable test to determine the HPV status of oropharyngeal tumours. This may enable risk stratification of patients to inform treatment decisions, as well as further elucidating the molecular virology and mechanisms underlying the advantage in drug response and survival seen in HPV-associated HNSCC. In order to do this, one needs to better understand how HPV-induced oropharyngeal cancers evolve. It is well established that cervical cancer develops through increasingly severe grades of neoplasia, and understanding of the sequence of molecular changes underlying these events has supported implementation of screening programmes, which in turn have significantly reduced the mortality of cervical cancer in the Western world. ${ }^{20}$ Anal and penile carcinogenesis are also increasingly well described, with $>80 \%$ of anal cancers $^{21}$ and around $40 \%$ of penile cancers being HPV-associated. However, for oropharyngeal cancers, the equivalent precancerous lesions have yet to be defined. Good understanding of the transition from a transient to persistent HPV infection and then to cancer is also lacking, and a biomarker that would enable risk assessment of lesions to distinguish malignancy potential does not exist. There is increasing evidence that the risk of HPV-associated malignancies, such as anal and penile cancer, is higher in HIV-infected individuals and men who have sex with men (MSM). ${ }^{22}$ If the risk of HNSCC is similarly increased in these groups (and a recent study has shown a higher incidence of HPV-associated HNSCCs among HIV-positive individuals $^{23}$ ), these groups may stand to benefit most from any screening programme.

Although the effectiveness of HPV vaccination to protect against head and neck cancers is not yet proven, in some case series $>70 \%$ of oropharyngeal cancers test positive for high-risk HPV type-16. ${ }^{1}$ Immunisation against oncogenic HPV subtypes, introduced in the UK for girls in 2008 , is likely to transform the epidemiology of all HPV-associated cancers in the UK and in other countries where it has been introduced. Dramatic changes in the incidence of HPV-associated cancers are therefore to be expected. There are also several proposed changes to vaccination programmes that may further affect the incidence of $\mathrm{HPV}$-associated cancers. A nonavalent vaccine is currently in clinical trials, which would protect against high-risk HPV types not included in the current vaccines (Gardasil and Cervarix protect against HPV 16 and 18 and not HPV 31 and 33). In the UK, the decision not to vaccinate boys is being revisited by the Joint Committee on Vaccination and Immunisation, in part due to increasing evidence about the role of HPV in anal, penile, head and neck, and other cancers, and in part due to the lack of herd protection afforded to MSM. However, individuals currently infected with high-risk HPV in the oropharynx and the vast majority of the global population who have not been vaccinated remain at risk of developing HPV-associated head and neck cancer.

Contributors This work was conceived and written jointly by NF and ML.

Competing interests None.

Provenance and peer review Commissioned; internally peer reviewed. 


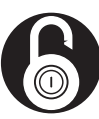

\section{OPEN ACCESS}

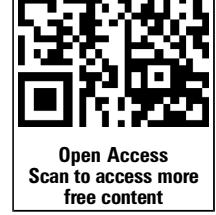

Open Access This is an Open Access article distributed in accordance with the Creative Commons Attribution Non Commercial (CC BY-NC 4.0) license, which permits others to distribute, remix, adapt, build upon this work non-commercially, and license their derivative works on different terms, provided the original work is properly cited and the use is non-commercial. See: http:// creativecommons.org/licenses/by-nc/4.0/

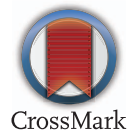

To cite Field N, Lechner M. Sex Transm Infect 2015;91:229-230.

Accepted 19 November 2014

Published Online First 22 April 2015

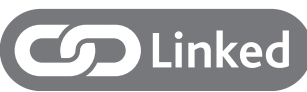

http://dx.doi.org/10.1136/sextrans-2014-051955

Sex Transm Infect 2015;91:229-230.

doi:10.1136/sextrans-2014-051808

\section{REFERENCES}

1 D'Souza G, Kreimer AR, Viscidi R, et al. Case-control study of human papillomavirus and oropharyngeal cancer. N Engl J Med 2007;356: 1944-56.

2 Tran N, Rose BR, O'Brien CJ. Role of human papillomavirus in the etiology of head and neck cancer. Head Neck 2007;29:64-70.

3 Rodriguez T, Altieri A, Chatenoud L, et al. Risk factors for oral and pharyngeal cancer in young adults. Oral Oncol 2004;40:207-13.

4 Gillison ML. Human papillomavirus-associated head and neck cancer is a distinct epidemiologic, clinical, and molecular entity. Semin Oncol 2004;31:744-54.

5 Chaturvedi AK, Engels EA, Anderson WF, et al. Incidence trends for human papillomavirus-related and -unrelated oral squamous cell carcinomas in the United States. J Clin Oncol 2008;26:612-19.

6 Chaturvedi AK, Engels EA, Pfeiffer RM, et al. Human papillomavirus and rising oropharyngeal cancer incidence in the United States. J Clin Oncol 2011:29:4294-301.

7 Nasman A, Attner P, Hammarstedt L, et al. Incidence of human papillomavirus (HPV) positive tonsillar carcinoma in Stockholm, Sweden: an epidemic of viral-induced carcinoma? Int I Cancer 2009; 125:362-6.

8 Garnaes E, Kiss K, Andersen L, et al. A high and increasing HPV prevalence in tonsillar cancers in Eastern Denmark, 2000-2010: the largest registry-based study to date. Int $\mathrm{I}$ Cancer Published Online First: 4 Oct 2014.

9 Marur S, D'Souza G, Westra WH, et al. HPV-associated head and neck cancer: a virus-related cancer epidemic. Lancet Oncol 2010;11:781-9.

10 Pytynia KB, Dahlstrom KR, Sturgis EM. Epidemiology of HPV-associated oropharyngeal cancer. Oral Oncol 2014;50:380-6.

11 Gillespie MB, Rubinchik S, Hoel B, et al. Human papillomavirus and oropharyngeal cancer: what you need to know in 2009. Curr Treat Options Oncol 2009;10:296-307.

12 Kreimer AR, Alberg AJ, Daniel R, et al. Oral human papillomavirus infection in adults is associated with sexual behavior and HIV serostatus. J Infect Dis 2004;189:686-98.
13 D'Souza G, Agrawal Y, Halpern J, et al. Oral sexual behaviors associated with prevalent oral human papillomavirus infection. J Infect Dis 2009;199: 1263-9.

14 Mercer CH, Tanton C, Prah P, et al. Changes in sexual attitudes and lifestyles in Britain through the life course and over time: findings from the National Surveys of Sexual Attitudes and Lifestyles (Natsal). Lancet 2013;382:1781-94.

15 Kreimer AR, Pierce Campbell CM, Lin H-Y, et al. Incidence and clearance of oral human papillomavirus infection in men: the HIM cohort study. Lancet 2013;382:877-87.

16 Fakhry C, Westra WH, Li S, et al. Improved survival of patients with human papillomavirus-positive head and neck squamous cell carcinoma in a prospective clinical trial. J Natl Cancer Inst 2008;100: 261-9.

17 Licitra L, Perrone F, Bossi P, et al. High-risk human papillomavirus affects prognosis in patients with surgically treated oropharyngeal squamous cell carcinoma. J Clin Oncol 2006;24:5630-6.

18 Hafkamp HC, Manni JJ, Haesevoets A, et al. Marked differences in survival rate between smokers and nonsmokers with HPV 16-associated tonsillar carcinomas. Int J Cancer 2008;122:2656-64.

19 England D.o.P.H., NHS Cervical Screening Programme.

20 Peirson L, Fitzpatrick-Lewis D, Ciliska D, et al. Screening for cervical cancer: a systematic review and meta-analysis. Syst Rev 2013;2:35

21 Frisch M, Glimelius B, van den Brule AJC, et al. Sexually transmitted infection as a cause of anal cancer. N Engl J Med 1997;337:1350-8.

22 Palefsky JM. Human papillomavirus-related disease in men: not just a women's issue. J Adolesc Health 2010;46(4 Suppl):S12-19.

23 Beachler DC, Abraham AG, Silverberg MJ, et al. Incidence and risk factors of HPV-related and HPV-unrelated Head and Neck Squamous Cell Carcinoma in HIV-infected individuals. Oral Oncol Published Online First: 6 Oct 2014. 